Meet-my-life

\title{
Die Wolken des Vergessens lichten
}

\section{Adrian Ritter}

Freier Journalist

\author{
Von der Flucht vor dem Nationalsozialismus zur Hausarztpraxis in der Schweiz: \\ Der 81-jährige Peter Marko hat im Rahmen des Projektes «meet-my-life.net» seine \\ Autobiographie geschrieben. Und wurde dafür mit einem Award ausgezeichnet.
}

Peter Marko war in den 1970er Jahren mit dem Aufbau einer Existenz in seiner neuen Heimat Schweiz beschäftigt. $\mathrm{Zu}$ beschäftigt, als dass er gleichzeitig ein offenes Ohr für die Geschichten seiner Mutter gehabt hätte. Er wusste, dass es viele traurige Geschichten über seine Herkunftsfamilie in der heutigen Slowakei zu erzählen gab. Damit wollte er sich das Leben nicht schwerer machen. Gleichzeitig verspürte er das Bedürfnis, über seine Erlebnisse in der neuen Heimat zu schreiben. Seine Texte wurden ab 1981 unter anderem in der Schweizerischen Ärztezeitung veröffentlicht.

\section{Projekt «Meet-my-life.net»}

Mit den Geschichten über die Gegenwart wuchs dann trotzdem auch sein Interesse, mehr über seine Vergangenheit zu erfahren und diese ebenfalls schriftlich festzuhalten. Den geeigneten Rahmen dazu fand er im Projekt «Meet-my-life.net». Die nicht kommerzielle Autobiographie-Plattform hilft Interessierten, mittels Fragen einen Dialog mit sich selbst zu führen und ihr Leben zu dokumentieren. Das Schreibkonzept dahinter entstand aus der Universität Zürich heraus.

\section{Ein Leben voller Weltgeschichte}

Drei Jahre lang schrieb Peter Marko an seiner rund 160-seitigen Autobiographie mit dem Titel «Die Suche und das Finden». Er schildert darin seinen Werdegang

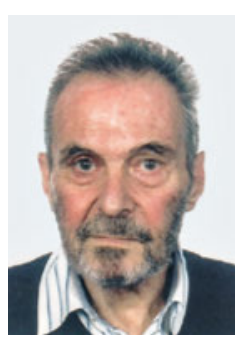

\section{Zur Person}

Peter Marko wurde 1937 in derTschechoslowakei geboren und studierte dort Medizin. Mithilfe eines Stipendiums ging er 1967 zunächst nach Freiburg und Aachen in Deutschland. 1970 kam er dann in die Schweiz, wo er promovierte und viele Jahre als Hausarzt tätig war. Heute lebt er mit seiner Frau in St. Gallen. Er hat zwei Kinder und vier Enkelkinder.

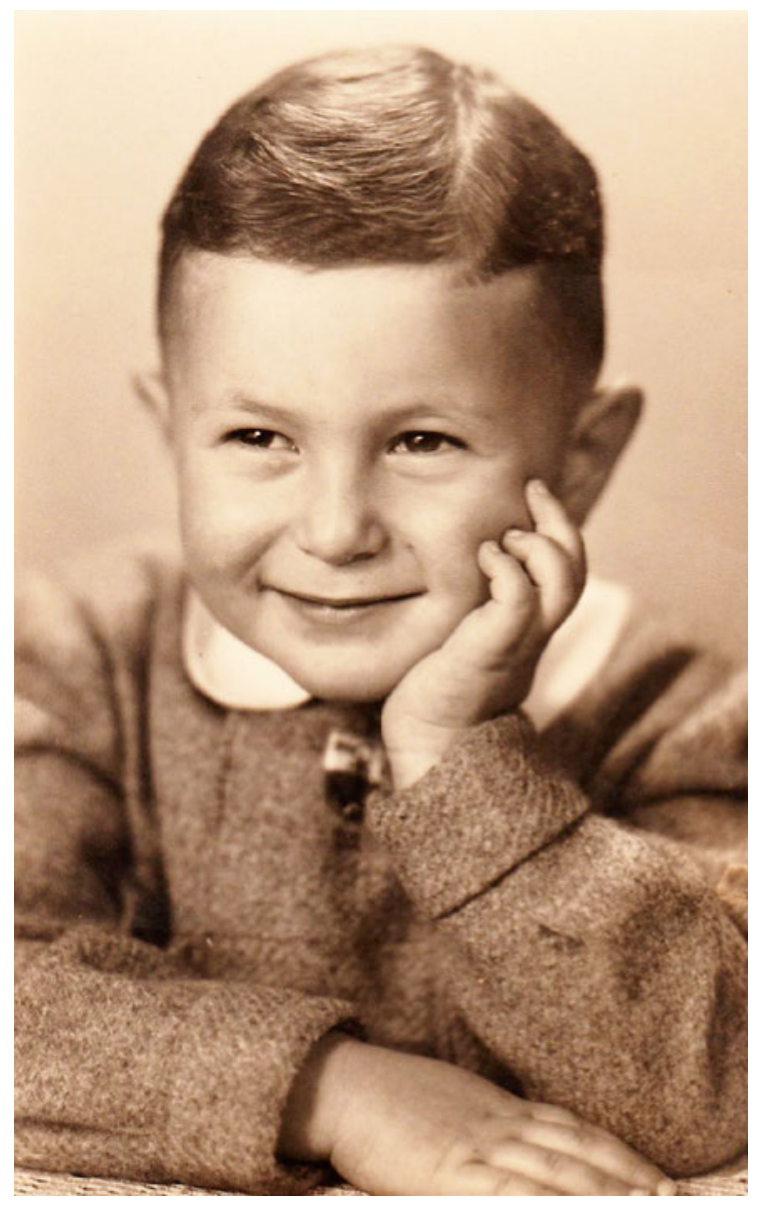

Peter Marko im Alter von zwei Jahren.

von der Geburt 1937 bis zur Gegenwart als pensionierter Hausarzt in St. Gallen.

\section{Gefährliche Zeiten}

Bereits der Beginn seines Lebens als Teil einer jüdischen Familie in der damaligen Tschechoslowakei war überschattet vom Zeitgeschehen. Als seine Mutter mit ihm schwanger war, wollte der Vater zuerst eine Abtreibung. Er sah gefährliche Zeiten für Juden aufziehen 
und vermutete, dass dies nicht auf Deutschland beschränkt bleiben wird. Der Onkel - Allgemeinmediziner - verweigerte allerdings die Abtreibung und auch der Rest der Familie widersprach dem Vater.

\section{Menschen verschwinden}

Mit den gefährlichen Zeiten sollte der Vater allerdings Recht behalten. «Das Verschwinden von wichtigen [...] Menschen aus meinem Leben wurde zur Regel. Es begannen die Transporte», schreibt er in seiner Biographie über die Deportation jüdischer Menschen auf Druck von Nazideutschland. Durch die Konversion zum Christentum blieb die Familie vorerst davon verschont - Peter Marko war danach auch längere Zeit praktizierender Christ.

\section{Flucht in die Berge}

Als die deutsche Wehrmacht im Zweiten Weltkrieg die Slowakei besetzte, flohen die Eltern mit den Kindern in die Berge und lebten monatelang in einem Bunker. Nach dem Krieg war die Familie erst begeistert darüber, bei der Verwirklichung des sozialistischen Traums mithelfen zu können. Der Traum platzte allerdings, als Misstrauen, Verhaftungen und Angst auch im neuen Regime um sich zu greifen begannen: «Es herrschte Unterdrückung und Verfolgung. Kein Wunder, dass wir enttäuscht waren», schreibt er.

\section{Per Stipendium in die BRD}

Peter Marko hatte inzwischen in Bratislava Medizin studiert und arbeitete als Assistent am Biochemischen

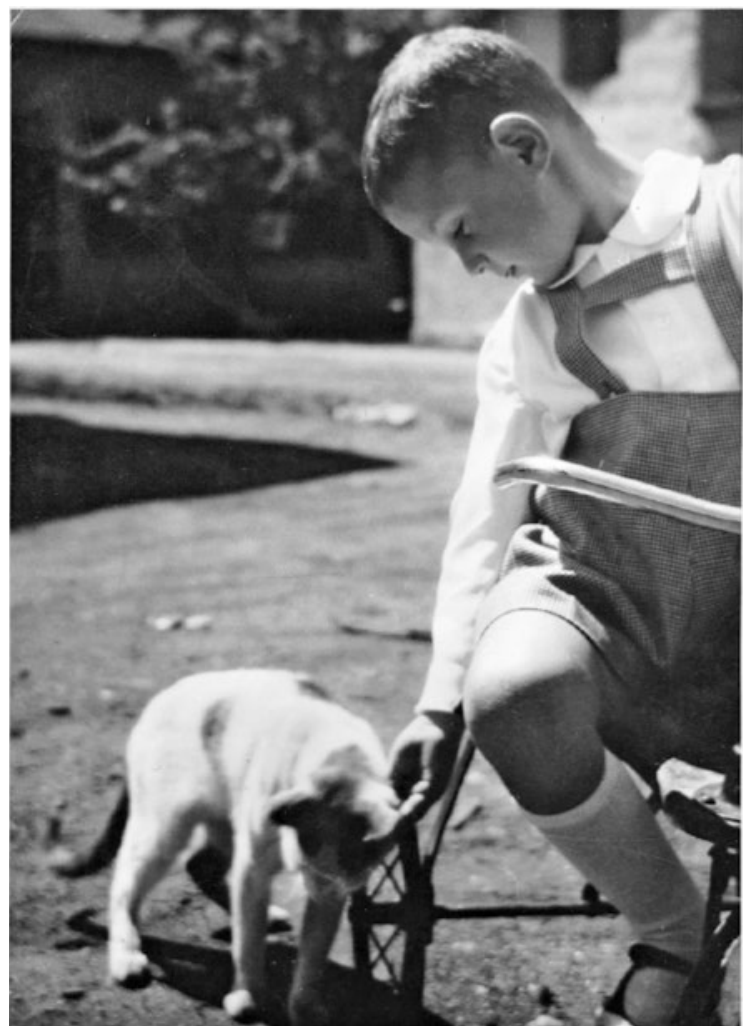

Diese Aufnahme entstand, als Peter Marko fünf Jahre alt war.

Institut. 1967 nutzte er ein Humboldt-Stipendium, um sich in die Bundesrepublik Deutschland abzusetzen. Von dort zog er 1970 in die Schweiz. Hier war er erst in der Hirnforschung und anschliessend als Hausarzt in Zweisimmen, Romanshorn und später in St.Gallen tätig.

\section{Auszeichnung mit dem ersten Schweizer Autobiographie-Award}

Seine Erlebnisse als Arzt, die er unter anderem in der Schweizerischen Ärztezeitung und der Zeitschrift Primary and Hospital Care veröffentlichte, sind ebenfalls Teil der Autobiographie. Für diese wurde er im Februar 2018 mit dem ersten Schweizer Autobiographie-Award von «Meet-my-life» ausgezeichnet. Geschrieben hat er sein Werk vor allem auch für seine Nachkommen - auf dass sie ihn und sich selber besser verstehen mögen Jetzt will er seine Aufzeichnungen auch in die Muttersprache übersetzen, denn: «Ich möchte meine Autobiographie auch in der Slowakei veröffentlichen.»

Die Autobiographie von Peter Marko

\footnotetext{
... ist frei zugänglich unter www.meet-my-life.net
} 